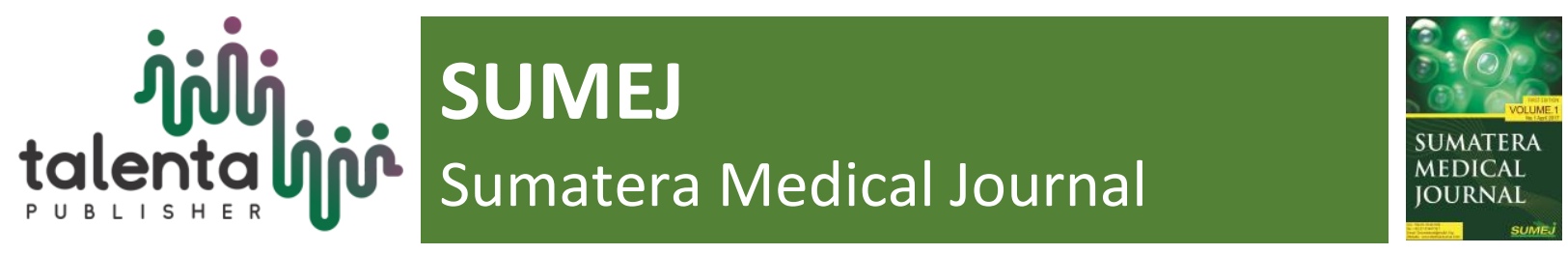

\title{
Polyphenols as Natural Antioxidants in Skin Aging
}

\author{
S. W. Yenny ${ }^{*}$, Y. E. Suryani ${ }^{2}$ \\ ${ }^{1,2}$ Departement of Dermatovenereology, Faculty of Medicine, Andalas University, Padang, West \\ Sumatera
}

\begin{abstract}
Skin aging is a complex biological process influenced by a combination of intrinsic and extrinsic factors, leading to cumulative alterations of skin struture, function and appearance. Polyphenols represent a superfamily of diverse naturally occurring phytochemicals. Current research reveals that phenolic compounds in plants possess high antioxidant activity and free radical scavenging capacity and can prevent the body from oxidative damage over human life span. This review focuses on present understanding of skin aging and the effects of polyphenols in the context of anti-aging activity
\end{abstract}

Keyword: Natural Antioxidants, Polyphenols, Skin Aging

Received 03 June 2020 | Revised 27 July 2020 | Accepted 12 August 2020

\section{Introduction}

As humans age, the accumulation of damages caused by environmental factors such as reactive oxygen species (ROS), sun exposure, high stress levels, environmental pollution, cigarette smoking, alcohol, and drug abuse attribute to the effect of skin disease and skin aging.1 At the molecular level, oxidation caused by ROS can produce lipid peroxidation, damage membrane proteins and mutations of deoxyribo nucleic acid (DNA), which play an important role in changing the structure, function and aesthetics of the skin, and can initiate the development of various diseases. 2 The skin becomes thinner, sweat- and oil- secreting glands in the skin decrease, leaving the skin dry and thin. Production of the proteins collagen and elastin in the skin also declines, leading to decreased firmness and formation of wrinkles. Melanin, the pigment that gives skin its color, becomes unevenly distributed causing freckles and age spots. ${ }^{1}$

Active components and phytochemicals for skin care have been investigated extensively aiming to intervene with the exogenous and endogenous aging agents to slow down aging and other skin deterioration effects. One of the notable phytochemicals that have been reported to provide such therapeutic skin care functions is polyphenols. Polyphenols (polyphenolic compounds) are

\footnotetext{
*Corresponding author at: Department of Dermatovenereology, Faculty of Medicine, Andalas University, Padang, West Sumatera

E-mail address: satyawidyayenny@med.unand.ac.id
} 
naturally occuring phytochemicals containing conjugated phenol ring(s) as a common molecular structure, that have been believed to be essential micronutrients. Over the past 20 years there have been several studies which state that a diet rich in polyphenols is associated with a protective effect against various diseases related to aging. ${ }^{4,5,6}$ In vitro, polyphenols have antioxidant, anticollagenase and anti-elastase activities. Polyphenolic extracts are attractive ingredients for cosmetics and pharmacy due to their beneficial biological properties. Further, important to know the natural sources of polyphenols and physicochemical aspects of polyphenols, before clinicians use them in their daily practices. ${ }^{3,7}$

\section{$2 \quad$ Skin Aging}

Skin aging is a complex, biological phenomenon consisting of two components; intrinsic (chronological) aging, which is largely genetically determined and extrinsic aging caused by external factors, mostly chronic exposure to UV radiation (premature photoaging). ${ }^{8}$

In chronological aging, skin is smooth and without any evident spots (hyper-and hypopigmentation), with normal topography, mostly with distinct mimic wrinkles and lines. Histologically, there is atrophy of the epidermis and dermis, reducing the number of fibroblasts and mast cell, and increase of collagen fibers and relationship between collagen III and collagen I. Skin that is chronically expose to sunlight (face, neck, chest, exposed hand skin) is characterized by a large number of signs of photoaged skin, such as pigmented lesions (lentigo), loss of muscle tone and elasticity, increased fragility, weakness of the blood capillaries-visible telangiectasias and keratosis. Histopathologically, elastosis can be observed in the dermis, as well as athrophy of the epidermis, clear changes in the appearance of collagen, and elastic fiber fragmentation (higher content of collagen and soluble collagen). Elastic fibers are also fragmented, irregularly meshed and calcified. ${ }^{9,10}$

The accumulation of ROS and damage caused by ROS is one of the most important mechanism that leads to cellular aging. There are many potential target molecules in the skin layers that may be candidates for oxidative stress, such as lipids, proteins, carbohydrates and DNA. A large number of chemical reactions can occur between ROS and these potential target molecules in the skin, and that can lead to the variety of structural and functional injuries to the skin. Cumulative photodamage of the skin contributes to photoaging of the skin, which can result in falling levels of antioxidant enzymes and antioxidant defense capacity, all leading to the accumulation of oxidative damage and products, which are the markers of oxidative stress. ${ }^{10}$

\section{Structure and classification of polyphenols}

The term of 'polyphenols' includes a group of substances, which all have more than one phenolic hydroxyl group, bounded to one or more benzene ring systems. ${ }^{3}$ Therefore, depending on the number of phenolic rings and the interconnection of these rings, the polyphenolic family is 
divided into several major classes, with thousands of members in each class, including flavonoids, phenolicacids,stilbenes, and lignans (figure 1). Flavonoids are the largest class in the group and can be categorized as flavonols (e.g., quercetin, kaempferol), flavones (e.g., apigenin, luteolin), flavanones (e.g., naringenin and hesperetin), isoflavones (e.g., genistein and daidzein), flavanols (e.g., catechin, epigallocatechinepigallocatechin gallate), anthocyanins (e.g., cyandin, malvidin), and flavonolignans. Phenolic acids are the second most common class of polyphenols after flavonoids and are present in coffee and black tea. They are primarily classified as benzoic and cinnamic acid derivatives. Stilbenes are not common in plants and are only produced upon pathogen invasion. Finally, lignans are phytoestrogens that are highly abundant in flaxseed and flaxseed oil, with the best-known compounds being secoisolariciresinol and matairesinol. The structure of polyphenols is an important determinant of their bioavailability, pharmacokinetic profile, interactions with biomolecules and efficacy. ${ }^{1,11}$

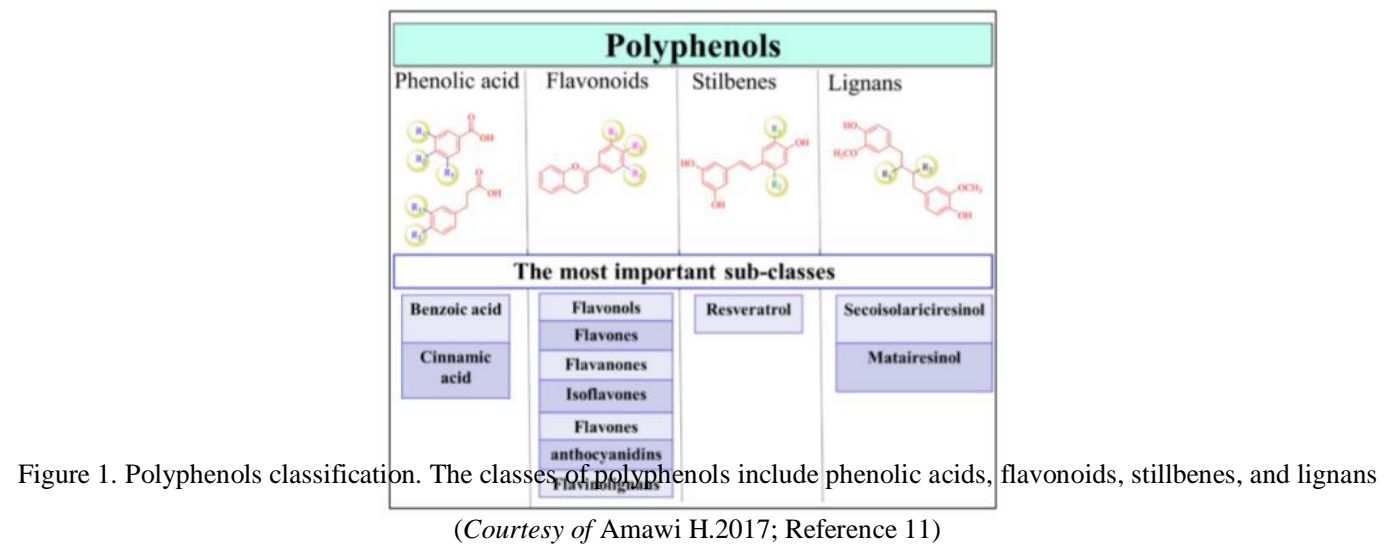

\section{Biological activities of polyphenols}

Among the notable bioactivities of phenolic compounds, the antioxidant activities have been widely studied, including scavenging of free radicals, inhibition of lipid oxidation, reduction of hydroperoxide formation, and so on. Polyphenols may also function as antioxidants through their effects on plasma, membranes, transcription factors and enzyme activities in vivo. Epigallocathecin 3-gallate (EGCG) has 100 times more effectiveness than vitamin C and was 25 times better than vitamin $\mathrm{E}$ in protecting cells and DNA from damage. This content also has antioxidant potential twice as large as resveratrol, which causes oxidation mediated by $\mathrm{Cu} 2+$ from low density lipoprotein (LDL) was inhibited and reduced tertiary butyl hydro peroxide which caused lipid peroxidation and inhibited the production of ROS derived from NADPHcytochorme P450. ${ }^{12,13}$

Breakdown and disorganization of extracellular matrix proteins like collagen, fibronectin and elastin are main characteristics of skin aging due to the enhanced activation of proteolytic enzymes such as collagenases and elastases. Inhibition of their enzymatic activities by natural plant compounds might be a promising approach to prevent extrinsic skin aging. Especially 
polyphenols are supposed to interact with those enzymes due to their molecular nature. ${ }^{13}$ Wittenauer (Germany,2015) investigated extracts of pomace from Riesling grapes. Crude grape pomace extract showed a dose-dependent inhibitory activity against both enzymes with IC-50 (inhibition collagenase) values of $20.3 \mu \mathrm{g} / \mathrm{ml}$ and $14.7 \mu \mathrm{g} / \mathrm{ml}$ for collagenase and elastase activity, respectively. ${ }^{14}$

The ability of polyphenols as photoprotectors are important in their use in cosmetic products. The sun protection factor (SPF) from flavonoids, stylbene and hydroxycinamic acid derivatives, is determined from 7 to 29, based on minimal SPF values (SPF 2-12) and moderate (12-30). In addition, the ability to prevent or reduce photodamages due to UV makes these natural polyphenols as a relevant topical ingredient. ${ }^{8}$ Potapovich et al. showed that therapy in human epidermal keratinocytes after UV exposure with natural polyphenols (resveratrol, quercetin, verbascoside) was effective in eliminating excess peroxide production and inflammatory mediators in these cells. ${ }^{15}$ This research shows that polyphenol extract could be a useful ingredient for sunscreen and cosmetic products after uv exposure. Polyphenols have also been shown to have anti-carcinogenic effects in certain types of skin tumors, but only a few clinical studies are available. ${ }^{12}$

\section{Source of polyphenols}

\section{a. Grapes (Vitis vinifera)}

Grape is a phenol-rich plant, and these phenolics are mainly distributed in the skin, stem, leaf and seed of grape, rather than their juicy middle sections. Total concentration of phenolic compounds were about 2178.8, 374.6, 23.8, and $351.6 \mathrm{mg} / \mathrm{g}$ GAE (gallic acid equivalent) in seed, skin, flesh, and leaf, respectively. The total phenolic content of grape skins varied with cultivar, soil composition, climate, geographic origin, and cultivation practices or exposure to diseases, such as fungal infections. The compounds mainly included proanthocyanidins, anthocyanins, flavonols, flavanols, resveratrols and phenolic acids. Proanthocyanidins are the major phenolic compounds in grape seed and skin of grape. Anthocyanins are pigments and responsible for the color of grape fruits, and flesh did not contain anthocyanins. In red wine, anthocyanins and flavonoids are the major two groups of phenolic compounds, and (+)-catechin is an abundant flavonoid. ${ }^{16}$

In a study investigating the effect of grape seed extracts on the aged-associated accumulation of oxidative DNA damage in male albino rats of Wister strain, Balu et al. reported that grape seed extracts inhibited the accumulation of age-related oxidative DNA damage products such as 8-hydroxy-20-deoxyguanosine (8-OHdG) and DNA protein cross-links in spinal cord and in various brain regions including the striatum, cerebral cortex, and hippocampus. ${ }^{17}$ Selka (Algeria, 2019) assessed the antioxidant activity of Vitis vinifera, the polyphenol contained in it have antioxidant, anticancer, anti-inflammatory, anti-aging and antimicrobial effects. This 
content can be given both orally and topically to get the photoprotection effect. The antioxidant mechanism of polyphenol compounds were based on their ability to donate hydrogen atoms and the ability to bind metal ions. After donating one hydrogen atom, the phenolic compound becomes a stable compound. ${ }^{18}$

\section{b. Green tea extract (Camellia sinensis O. Ktze)}

Green tea contained of polyphenols (90\%), amino acids (7\%), theanine, proanthocyanidins, and caffeine (3\%). The main polyphenol content in green tea extract consists of epigallocathecin 3-gallate (EGCG), epigallocathecin (EGC), epicathecingallate (ECG), epicathechin (EC) and gallocathecin (GC). Among these components, EGCG has the highest level of catechin, about $50-80 \%$ of the total catechins in green tea, is considered as a major contributor in inhibiting collagenase activity, which has an anti-wrinkle effect. The polyphenols in green tea have 100 times more effective than vitamin $\mathrm{C}$ and 25 times more effective than vitamin $\mathrm{E}$ in inhibiting free radicals, so until now green tea widely use as a therapeutic option in the prevention of various disease. ${ }^{19}$ The high polyphenol content in green tea can also protect the skin from the premature aging which mainly caused by UV exposured, through its function as anti- melanogenic, anti-wrinkle, antioxidant, anti-inflammatory effects and prevents immunosuppression. ${ }^{20}$

Widiyowati H (Denpasar, 2017) conducted an in vitro study, showed that the used of of cream containing green tea extract that $70 \%$ could prevent the reduction in the amount of collagen dermis and increase Matrix metalloproteinase-1 (MMP-1) expression in Balb/C mice that was given ultraviolet B exposured. ${ }^{21}$ Another study, performed on 42 Korean women by applying green tea extract to wrinkles on the corner of the outer eye (crow's feet), twice daily for 8 consecutive days, showed that green tea extract can inhibit free radical activity and has an antiwrinkle effect. ${ }^{19}$ A placebo-controlled blind study conducted in women aged 25-75 years who were given oral supplementation of $250 \mathrm{mg}$ of green tea polyphenols for two years, showed significant improvements effect on facial skin and controlled erythema. Besides it can be consumed orally either through green tea itself or in the form of various supplements in circulation. Green tea extracts can also be added to various product formulations such as soap, exfoliating, masks, facial toner, lip balm and body scrubs. ${ }^{12,19}$

\section{c. Rice (Oryza sativa)}

Rice, being one of the most produced and consumed cereals in the world, has an important role in the relation between the diet and health. Several compounds with antioxidant activity have been identified in rice, including phenolic compounds, tocopherols, tocotrienols and $\gamma$ - 
oryzanol. The phenolic compounds are mainly associated with the pericarp in rice, hence, the milling process reduces the concentration of these compounds in the grain. Besides, grains with darker pericarp colour, such as red and black rice, contain higher amounts of polyphenols. ${ }^{22}$

High total polyphenol content in rice water is a bioactive compound that's rich in antioxidants and other biological activities, such as enzyme inhibition. Phenolic compounds can act as antioxidants by different mechanisms, including free radical scavenger and inhibition of prooxidant enzymes, such as tyrosinase and elastase. Therefore, rice water can reduce the formation of intracellular ROS induced either by chemical compounds $(\mathrm{H} 2 \mathrm{O} 2)$ or by UV light, through in vitro studies on human keratinocytes and animal study. ${ }^{23}$

\section{d. Seaweed (Sargassum sp.)}

Sargassum sp. contains bioactive compounds such as flavonoids, triterpenoids, polyphenols, chlorophyll, carotenoids and alkaloids which can be used as a source of natural antioxidants. Sargassum sp. has an inhibition percentage to reduce free radicals at $81.35 \%$ and has a total phenolic compound of $127.4 \mathrm{mg} / \mathrm{g}$. Fukosantin is part of the main polyphenols found in seaweed, this compound has the potential to be developed as a nutritional especially as an antioxidant and chemopreventive agent because of its ability to reduce free radicals. These compounds are widely applied for skin care cosmetics products, because they can function as emulsifiers, skin whitening, anti-aging, anti-wrinkle, prevent allergies, or as antioxidant. ${ }^{24}$

Polyphenols total dietary intake could be as high as $1 \mathrm{~g} / \mathrm{d}$, which is much higher than of all other classes of phytochemicals and known dietary antioxidants. They are mostly found in fruits and plantderived beverages, vegetables, cereals, chocolate and dry legumes are also sources for the total polyphenol intake..$^{7,11,13}$

Phlorizin belongs to the group of dihydrochalcones, a type of flavonoids and it is naturally occurring in some plants. It could be found in the bark of pear (Pyrus communis), apple, cherry and other fruit trees. Its anti-aging effects have only been reported in the last years. Investigations of the effects of phlorizin on lifespan of the yeast Saccharomyces cerevisiae showed an improvement of the viability of the yeast, which was dose-dependent under oxidative stress. ${ }^{11}$

\section{Conclusions}

Continuous exposure to UV light on human skin, there can be several pathobiological processes in cells, one of which is skin aging. Actually in the human body itself has produced antioxidants in the prevention of skin aging, but with age, increased metabolism and increased ROS accumulation, exogenous antioxidants are needed to meet the body's needs. Polyphenols are 
phytochemical that one of essential micronutrients thus attracting the attention of many dermatologist in effort to prevent and protect againts various problem related to skin aging.

\section{REFERENCES}

[1] Ji J, et al. Age-deterring and skin care function of a polyphenol rich sugarcane concetrate. Cosmetics. Australia. 2020; 7(30): 1-17.

[2] Stojiljkovic D., Pavlovic D., Arsic I. Oxidative stress, akin aging and antioxidant therapy. Scientific Journal of the Faculty of Medicine in Nis. Serbia. 2014; 31(4): 207-217.

[3] Zilich OV, Weisz US, Eisner P, Kerscher M. Polyphenols as active ingridients for cosmetic products. International Journal of Cosmetic Science. Germany. 2015; 37: 455-464.

[4] Peres PS, Terra VA, Guarnier FA, et al. Photoaging and chronological aging profile: understanding oxidation of the skin. J Photochem Photobiol B. Brazil. 2011;103: 93-97.

[5] Putri M.G., Wijaya L., Sasmita P.K. Melatonin as an antiaging skin due to ultraviolet light. Damianus journal of medicine. Jakarta. 2015; 14(1): 67-79.

[6] Bensalem J, Dal-pan A, Gillard E, Calon F, Pallet V. Protective effects of berry polyphenols against age-related cognitive impairment. Nutrition and Aging. Canada. 2015; 3: 89-106.

[7] Jadoon S, et al. Anti-aging potential of phytoextract loaded pharmaceutical creams for human skin cell longetivity. Oxidative Medicine and Cellular Longevity. Irak. 2015; 1-17.

[8] Kern ML, Chien AL, Kang S. Skin Aging. In: Kang S,et al, Eds. Fitzpatrick’s dermatology 9 th edition. New York: Mc Graw Hills Company; 2019. p. 1779-1791.

[9] Ahmad Z, Damayanti. Penuaan kulit: patofisiologi dan manifestasi klinis. Berkala Ilmu Kesehatan

Kulit dan Kelamin. Surabaya. 2018; 3(3): 208-215.

[10] Djuanda S.R., Novianto E., Boediardja S.A., Jusman S.W. Peran stres oksidatif pada penuaan kulit secara intrinsik. MDVI. Jakarta. 2012; 39(9): 127-133.

[11] Amawi H, Ashby CR, Samuel T, Peraman R, Tiwari A. Polyphenolic nutrients in cancer chemoprevention and metastasis: role of the epithelialto-mesenchymal (emt) pathway. Nutrients. Turki. 2017; 911(9): 1-23.

[12] Li An, et al. Resources and biological activities of natural polyphenols. Nutrients. China. 2014; 6: 6020-6047.

[13] Teplova VV, et al. Natural polyphenols: biological activity, pharmacological potential, means of metabolic engineerng (review). Applied biochemistry and microbiology. Russia. 2018; 54(3) : 221-237.

[14] Wittenauer J, Mackle S, Submann D, Weisz U, Carle R. Inhibitory effects of polyphenols from grape pomade extract on collagenase and elastase activity. Fitoterapia. Germany. 2015; $1-9$.

[15] Petruk G., Giudice R.D., Rigano M.M. Antioxidants from plants protect against skin photoaging. Oxidative Medicine and Cellular Longevity. Swedia; 2018: 1-11.

[16] Xia EQ, DengGF, Guo YJ, Li HB. Biological activities of polyphenols from grapes. Int J Mol Sci. China. 2010; 11: 622-646. 
[17] Balu M, Sangeetha P, Murali G, Panneerselvam C. Modulatory role of grape seed extract on age-related oxidative dna damage in central nervous system of rats. Brain Res Bull. 2006; 68(6): 469-73.

[18] Selka MA, Achouri MY, Chenafa A, Toumi H. The study of polyphenolic compounds profile and antioxidant activity of vitis vinifera l. leaves from western regions of Algeria. IJP. Algeria. 2019; 6(1): 20-29.

[19] Roh E, et al. Molecular mechanisms of green tea polyphenols with protective effects against skin photoaging. Critical reviews in food science and nutrition. Korea. 2017; 57(8): 1631-1637.

[20] Rajbhar K, Dawda H, Mukundan U. Tea polyphenols for skin care. Research J. Topical and Cosmetic. India. 2015; 6(1): 1-6.

[21] Widiyowati $\mathrm{H}$, et al. The administration of green tea extract cream (Camellia sinensis) can prevent the decrease in the amount of collagen dermis and increase levels of metalloproteinase-1 matrix in balb-c mice exposed to ultraviolet light.. IJAAM. Denpasar. 2017; 1(1): 1-16.

[22] Walter M, Marchesan E. Phenolic compounds and antioxidant activity of rice. Braz Arch Biol Technol. Brazil. 2011; 54(2): 371-77.

[23] Palungwachira P, dkk. Antioxidant and anti-inflammatory properties of anthocyanins extracted from oryza sativa 1 . in primary dermal fibroblasts. Oxidative Medicine and Cellular Longevity. Thailand. 2019; 1-18.

[24] Sedjati S, Suryono, Santosa A, Supriyantini E, Ridlo A. Antioxidant activity and content of phenolic compounds in brown macroalgae Sargassum sp. Jurnal Kelautan Tropis. Semarang. 2017; 20(2):117-123.

[25] Jadoon S, et al. Anti-aging potential of phytoextract loaded-pharmaceutical creams for human skin cell longetivity. Oxidative Medicine and Cellular Longevity. Iraq. 2015; 1-17. 